\title{
Editorial: The 9th international workshop on modelling nutrient digestion and utilisation in farm animals
}

\author{
I. A. M. A. Teixeira ${ }^{1 \dagger} \odot$ and D. P. Poppi ${ }^{2}$ \\ ${ }^{1}$ School of Agricultural and Veterinarian Sciences, UNESP - Universidade Estadual Paulista, Jaboticabal, SP 14884-900, Brazil; ${ }^{2}$ School of Agriculture and Food Sciences, \\ University of Queensland, Gatton 4343, Australia
}

The 9th International Workshop on Modelling Nutrient Digestion and Utilisation in Farm Animals (MODNUT) was held in Ubatuba, Brazil in September 2019. The conference was closely associated with the International Symposium on Energy and Protein Metabolism and Nutrition (ISEP) and continued a tradition of close association with other main symposia. Since its fruition, in 1979, MODNUT has been held quinquennially across the world; however, it was the first time it was held in South America. The workshop has a strong tradition, evolved over the years, of being a forum for the development of new biological and mathematical ideas and methods.

Scientists from 16 countries joined the MODNUT in Brazil. The oral communications and the poster sessions reported on digestion and metabolism in a variety of farm animal species and as such looked for common ideas and mathematical methodology for application across farm species. The short scientific communications were published in Advances in Animal Biosciences, 2019, volume 10 , issue 2.

There were 21 papers accepted for publication in this issue. These followed the themes of Advances in modelling methodology, Modelling feed intake and nutrient digestion, utilisation and metabolism, and System models for production and environmental impact. Invited sessions challenged participants on the biological basis of mathematical models and the methodology by which to analyse and incorporate large data sets within the models. These issues and the ways forward were outlined by Sauvant et al. (2020), who reviewed good practices and potential pitfalls in applying a meta-analytical approach in animal sciences, and by Ellis et al. (2020) who highlighted the role of mechanistic models in the era of big data and intelligent computing, among others. Altogether, the papers published in this special issue will help the understanding about new approaches in modelling, as well as advance the application of modelling to animal science and inspire you to apply modelling in future studies.

There were two activities of note. A series of speakers outlined the contribution of Professor Jim France to the

† E-mail: izabelle.teixeira@unesp.br workshop since its inception and the field of mathematical models, noting his achievements and various awards. Of particular note was the long involvement of Professor France to the series of workshops starting with the very first workshop, the many books and papers in which he contributed and the strong mentoring role he has played in the career of many students, postdoctoral fellows and scientists. The field of mathematical modelling in farm animals owes much to Professor Jim France, and this was acknowledged at the meeting by the special session in his honour, 'Advances in modelling, Jim France Tribute'. A second major activity was the conduct of workshop sessions by Dr Kristan Reed on Linear models and meta-regression and $\mathrm{Dr}$ Mark Hanigan on Mechanistic models. This enabled participants to gain experience in the most recent accepted methodology in approaching these problems.

Finally, the next international committee under the chair of Dr Jan Dijkstra and the next local committee under the chair of Dr Antonello Cannas met and the next workshop will be held in Sardinia in 2022, closely associated with the timing of the next ISEP conference.

\section{Acknowledgements}

A special thanks to the staff of UNESP for organising and conducting the conference and a series of sponsors to enable the event to occur. We would also like to express our gratitude to the guest editors for their time and dedication to handle all the submissions, as well as to the reviewers who contributed to this special issue. And last but not least, we are grateful to those scientists that have blazed the trail before us and proposed and held this forum to discuss the application of modelling across multiple disciplines of animal science for the last 40 years.

(1) I. A. M. A. Teixeira 0000-0002-7432-867X

(1) D. P. Poppi 0000-0002-9116-1832

\section{Declaration of interest}

None. 
Teixeira and Poppi

\section{Ethics statement}

None.

\section{Software and data repository resources}

None.

\section{References}

Ellis JL, Jacobs M, Dijkstra J, van Laar H and Cant JP, Tulpan D and Ferguson N 2020 Synergy between mechanistic modelling and data driven models for modern animal production systems in the era of big data. Animal 14, s223-s237.

Sauvant $D$, Letourneau-Montminy MP, Schmidely $P$, Boval M, Loncke $C$ and Daniel JB 2020. Review: use and misuse of meta-analysis in animal science. Animal 14, s207-s222. 